\title{
Mucocyte distribution and relationship to particle transport on the pseudolamellibranch gill of Crassostrea virginica (Bivalvia: Ostreidae)
}

\author{
Peter G. Beninger*, Suzanne C. Dufour \\ Département de Biologie, Faculté des Sciences, Université de Moncton, Moncton, New Brunswick, Canada E1A 3E9
}

\begin{abstract}
To investigate particle transport mechanisms on the bivalve pseudolamellibranch gill, the mucocyte secretion types and distribution were determined for this organ in the eastern oyster Crassostrea virginica, and related to previous endoscopic data. Three adult oysters were collected from Shediac Bay (New Brunswick, Canada) in July 1994, immediately fixed, then dissected and processed for histology and whole mount mucocyte mapping using a modification of the periodic acidSchiff-alcian blue protocol. One type of mucocyte contained acid-secretion mucopolysaccharides (AMPS), while the other type contained neutral mucopolysacchandes (NMPS). A clear gradient in mucocyte density was observed from the plical crest to the trough; for all but the anteriormost 15 plicae the proportions of each mucocyte type remained constant; the 15 anteriormost plicae presented an increased proportion of AMPS. These proportions would produce a relatively viscous acid-dominant mucus after mixing on the ciliated gill surface. The principal filament troughs contained relatively few mucocytes, aligned on the median ridge. This arrangement could account for the observed range of particle velocities in these filaments. The results of the present study conform to a pattern of specialization of mucus types and functions on the diverse types of bivalve gill, depending on particle trajectory, transporting surface architecture, and dominant current flow.
\end{abstract}

KEY WORDS: Bıvalves Feeding - Mucus Gill

\section{INTRODUCTION}

Suspension feeding is a widespead trophic strategy in the marine environment. The Bivalvia constitute one of the major groups of suspension-feeding organisms; its members rely on their large gills for particle capture and transport to the peribuccal organs and mouth. Even some of the most primitive contemporary bivalves, the protobranchs, are facultative suspensionfeeders (Levinton 1977).

The use of mucus by suspension-feeding bivalves for ingestion of captured particles has been established; the origin of this mucus was inferred to be not only the peribuccal region but also the gill (Beninger et al. 1991, Beninger \& Le Pennec 1993). The bivalve gill presents 2 levels of physical complexity with respect to particle transport (Beninger et al. 1993): anatomical (types of

\footnotetext{
·E-mail: beningp@bosoleil.ci.umoncton.ca
}

filaments, types of inter-filamentar associations, location of ciliated particle transport tracts, distribution of mucocytes) and biochemical (types of secretions in mucocytes). The complementary techniques of video endoscopy and mucocyte mapping have spawned a fructuous field of research into the mechanisms of particle transport on bivalve gills (Table 1). Both techniques, applied to the homorhabdic filibranch Mytilus edulis and the heterorhabdic filibranch Placopecten magellanicus, have demonstrated substantial differences in function commensurate with mucocyte secretion type and distribution (Beninger et al. 1993). A detailed endoscopic study of particle transport in the heterorhabdic pseudolamellibranch Crassostrea virginica was performed by Ward et al. (1994); although extremely useful in the study of particle trajectories, endoscopy cannot reveal mucus secretions unless they and/or entrapped particles are clumped. Similarly, although visual differences may be observed, endoscopy cannot indicate what type of mucus is secreted in 
Table 1. Bivalve species in which particle transport has been studied using video endoscopy and mucocyte mapprng

\begin{tabular}{|c|c|c|c|}
\hline $\begin{array}{l}\text { Inter-filament } \\
\text { association }\end{array}$ & $\begin{array}{l}\text { Filament } \\
\text { type }\end{array}$ & Species & Source \\
\hline - Filibranch & Homorhabdic & Mytilus edulis & $\begin{array}{l}\text { Ward et al. (1993) } \\
\text { Beninger et al. (1993) }\end{array}$ \\
\hline - Filibranch & Heterorhabdic & Placopecten magellanicus & $\begin{array}{l}\text { Beninger et al. (1992) } \\
\text { Beninger et al. (1993) }\end{array}$ \\
\hline +Pseudolamellibranch & Heterorhabdic & Crassostrea virginica & Ward et al. (1994) \\
\hline${ }^{+}$Eulamellibranch & Homorhabdic & $\begin{array}{l}\text { Pyganodon cataracta } \\
\text { Mya arenaria }\end{array}$ & $\begin{array}{l}\text { Tankersley \& Dimock }(1992,1993) \\
\text { Ward et al. (1993) }\end{array}$ \\
\hline
\end{tabular}

the performance of which functions, nor can it identify the sites of such secretion and the relative importance of these secretions in specific areas of the gill.

Aliluughi some qualitative information exists concerning the relative abundances of mucocytes in the gills of Crassostrea virginica (Ribelin \& Collier 1977) and the European oyster Ostrea edulis (Owen 1978), the only quantitative data are the resuits of Nelsor (1960) indicating 'average' mucocyte numbers for the entire gill in histological sections for 3 oyster species. A thorough understanding of the mechanism of particle transport in the heterorhabdic pseudolamellibranch gill of the Ostreidae requires a more detailed and quantitative approach to mucocyte distribution and secretion type. The present study therefore seeks to determine mucocyte types and distribution on the $C$. virginica gill using mucocyte mapping, interpreting the results in the context of observed particle behaviour on the gills (Ward et al. 1994).

\section{MATERIALS AND METHODS}

Three adult oysters (size range 76.5 to $90.5 \mathrm{~mm}$, long axis) were collected on 13 July 1994 in Shediac Bay, New Brunswick, Canada. They were rapidly shucked in situ and fixed whole for $18 \mathrm{~h}$ in aqueous Bouin's solution, the recommended fixative for mucopolysaccharides (Cook 1990): saturated picric acid, $37 \%$ formaldehyde, glacial acetic acid 13:4:1. The whole tissue was rinsed under flowing water for $48 \mathrm{~h}$ prior to dissection. Pieces of the gill were removed from the anterior, middle, and posterior regions for both histological staining and whole mount staining. The periodic acidSchiff (PAS)-alcian blue histological procedure has been described in Beninger et al. (1993). (Technical note: Commercial albumin yields unsatisfactory section adhesion for this procedure with Crassostrea virginica gill tissue. Fresh egg albumin is necessary.) Histological sections revealed the presence of 2 distinct mucocyte types: those containing acid mucopolysaccharides only (AMPS) and those containing exclusively neutral mucopolysaccharides (NMPS).

The whole mount preparations were processed as per Beninger et al. (1993), with the following modification: after separating the ascending and descending gill lamellae by sectioning the intrafilamentar junctions, ine interfilamentar junctions between ordinary filaments in the dorsal and ventral regions were cut using microsurgical instruments, to allow the preparation to be spread more evenly on the slide and the staining to be more uniform. Trials showed that neutral secretion-containing mucocytes (PAS positive) were indistinguishable from the accumulated residual staining of other cells in the whole mount sections. The whole mount technique of Beninger et al. (1993) was therefore modified to include final staining for $1 \mathrm{~s}$ in $2.5 \%$ fast green, which allowed ready distinction between background staining, AMPS and NMPS. This was verified by alternate staining of $5 \mu \mathrm{m}$ serial sections. The whole mount preparations were thus stained using the following protocol: $1 \%$ alcian blue $8 \mathrm{GX}$ pH 2.5, 5 min; running water, 5 min; $1 \%$ periodic acid,

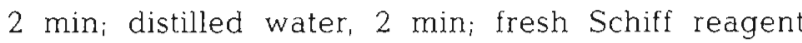
(Fisher Scientific brand; the reactivity of this compound varies greatly among suppliers), 4 s; $5 \%$ sodium metabisulfite, $1.5 \mathrm{~min}$; running water, $5 \mathrm{~min} ; 1 \%$ fast green, $1 \mathrm{~s}$; running water, 5 min. These times varied slightly between specimens. The stained gill pieces were spread over glass microscope slides using entomological needles and mounted using Farrant's medium and a coverslip. The edges of the coverslip were sealed with nail polish to prevent drying. The stained mucocyte colours were standardized using the Pantone universal colour guide (Beninger et al. 1993).

For each oyster, mucocyte quantification was effected in 4 zones along the dorso-ventral plane and for a complete plica in the antero-posterior plane (Fig. 1). As most oyster plicae contained 10 ordinary filaments $(\mathrm{OF})$ in addition to the 2 principal filaments $(\mathrm{PF})$, only 
A

Fig. 1. Crassostrea virginica. Schematic representation of gill, showing major structural features, preparatory sectioning for whole mounts, and mucocyte counting zones. (A) Longitudinal organization of a generalized gill filament, viewed along antero-posterior axis. AF: ascending filament; DCT: dorsal ciliated tracts; DF: descending filament; IFJ: intrafilamentar junctions; PG: ventral particle groove (ciliated tract); $1-4$ : location of mucocyte counting zones. Dashed line indicates sectioning of IFJs to allow separation of ascending and descending filaments. (B) Stereodiagram of the gill cut transversally. IJ: interfilamentar junctions; M: muscles responsible for contraction of principal filament, forming median ridge (MR); OF: ordinary filaments 1-10 of a plica; PF: principal filament. Dashed lines indicate sectioning of lJs to allow spreading of the plica on microscope slide

such plicae were selected for counting, in order to allow direct comparison of the results. Mucocyte counts were performed on longitudinal segments of gill filaments at $200 \times$ using a calibrated ocular micrometer. One count was performed in a dorso-ventral direction, and a second was performed in a ventrodorsal direction for each site. If the difference in mucocyte numbers of these 2 counts exceeded $5 \%$, a third count was performed, which in each case reduced the inter-count differences to less than $5 \%$; this procedure was performed on 53 out of 884 counts. The means of each zone for each filament were combined with the corresponding means of the 2 other animals, to obtain an overall mean and standard deviation for each filament in each zone. As Ward et al. (1994) reported the existence of a site on the anteriormost region of the gill which performed a specialized function, particular attention was paid to the anteriormost 15 plicae, which were counted individually (807 additional counts) In the rest of the gill excluding the anteriormost 15 plicae, preliminary counts showed similar profiles for pieces originating in the anterior, middle, and posterior regions of the gills; further counts were thus performed on whichever regions yielded the best staining results.

The diameters of 25 hapharzardly chosen mucocytes of each secretion type were measured in the whole mount preparations using an ocular micrometer, varying the focus to achieve maximum diameter for each mucocyte. The corresponding means and standard deviations were calculated; a 1 -tailed $t$-test was performed in order to determine whether the observed mean size difference between mucocyte types was statistically significant. A correction factor for shrinkage of fixed tissue was assessed by measuring the widths of 15 ordinary filaments from the median dorsal region of the descending external demibranch before and after fixation.
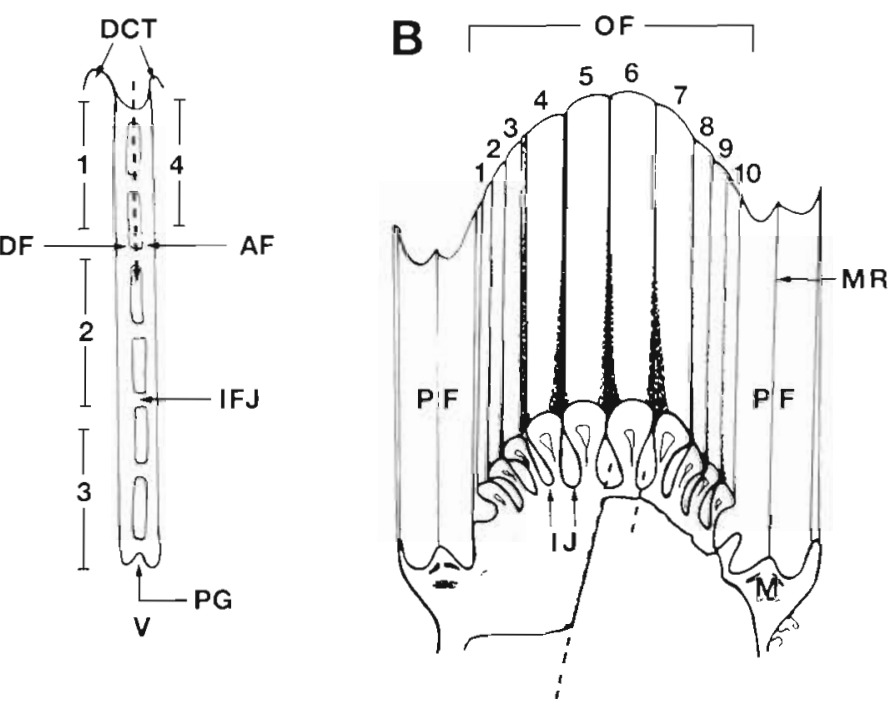

RESULTS AND DISCUSSION

Different types of mucopolysaccharide present different viscosities. The PAS-alcian blue staining technique permits a qualitative distinction between such secretions. NMPS are the least viscous, while AMPS are the most viscous (Grenon \& Walker 1978, 1980). Mixtures of these secretions present intermediate viscosities depending on the relative contributions of each.

Two types of mucocyte were present on the oyster gill: AMPS-containing cells and NMPS-containing cells. The results of the staining protocol are presented in Fig. 2, and the original colors in Table 2. In contrast to Mytilus edulis and Placopecten magellanicus (Beninger et al. 1993), no mucocytes contained a mixture of these 2 secretion types. However, the 2 mucus

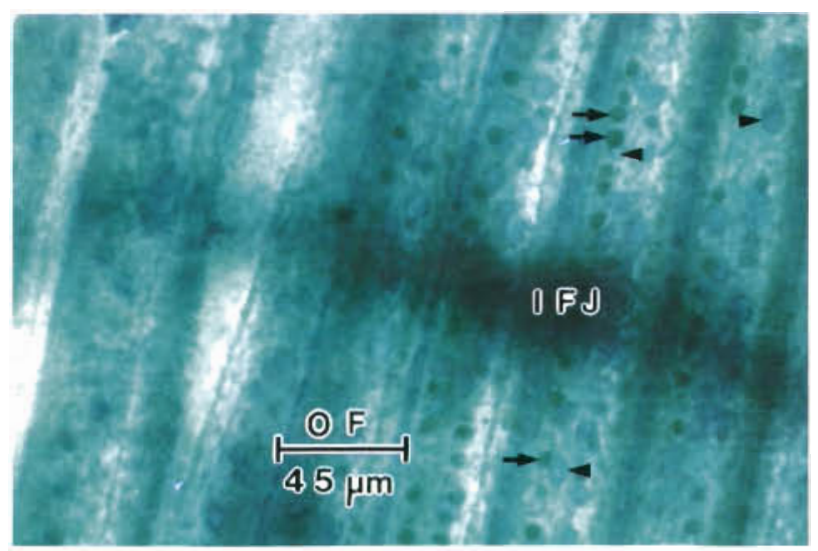

Fig. 2. Crassostrea virginica. Example of mucocyte staining on ordinary filaments. Original colours (see Table 2) may have been aitered by photograpinic plucessiny. iveutıả-secietioñ mucocytes $(\rightarrow$ ) and acid-secretion mucocytes $\rightarrow$ ) are visible. OF: ordinary filament; IFJ: interfilamentar junctions. Alcian blue - periodic acid-Schift — fast green stain 
Table 2. Secretion type, diameters and Pantone standard colors for stained mucocytes on Crassostrea virginica gill Tissue shrnkage $=14.75 \%$. P: probability

\begin{tabular}{|lclc|}
\hline $\begin{array}{l}\text { Mucocyte se- } \\
\text { cretion type }\end{array}$ & $\begin{array}{c}\text { Mean diameter } \\
\varnothing(\mu \mathrm{m}) \pm \mathrm{s}\end{array}$ & Color & $\begin{array}{c}\text { Pantone }^{3} \\
\text { standard colors }\end{array}$ \\
\hline Acid & $7.6 \pm 2.2$ & Blue & $3135 \mathrm{c}-3145 \mathrm{c}$ \\
Neutral & $6.7 \pm 1.9$ & Green & $355 \mathrm{c}-363 \mathrm{c}$ \\
& $P\left(\emptyset_{\text {Acid }}>\emptyset_{\text {Neutral }}\right)=0.06$ & \\
\end{tabular}

types must undergo mixing on the plical surface, since many of the captured particles are transported ventrally on the ordinary filament plicae to the ventral particle groove, producing the visibly viscous ventral mucus cord (Ward et al, 1994). The numerical dominance of AMPS mucocytes in all parts of the gill (Fig. 3) suggests a dominance of their secretions in the mixture, resulting in a mucus cord of relatively high viscosity. Although the mean diameter of the AMPS mucocytes was slightly larger than that of the NMPS mucocvtes, this difference was not statistically significant (Table 2).

It was not possible to obtain complete characterizations of the mucocyte distribution in the anteriormost 15 plicae, due to their progressively more compact structure and the attendant difficulties in sectioning the interfilamentar and intrafilamentar junctions. However, the 807 counts performed on these plicae showed a pattern identical to that in Fig. 3, with a greater dominance of AMPS. The ratio AMPS:NMPS ranged from 1.2:1 to $2: 1$ in the anteriormost 15 OF plicae, compared with $1: 1$ to $1.4: 1$ in the rest of the gill. The greater proportion of AMPS in the anteriormost plicae would
A

A
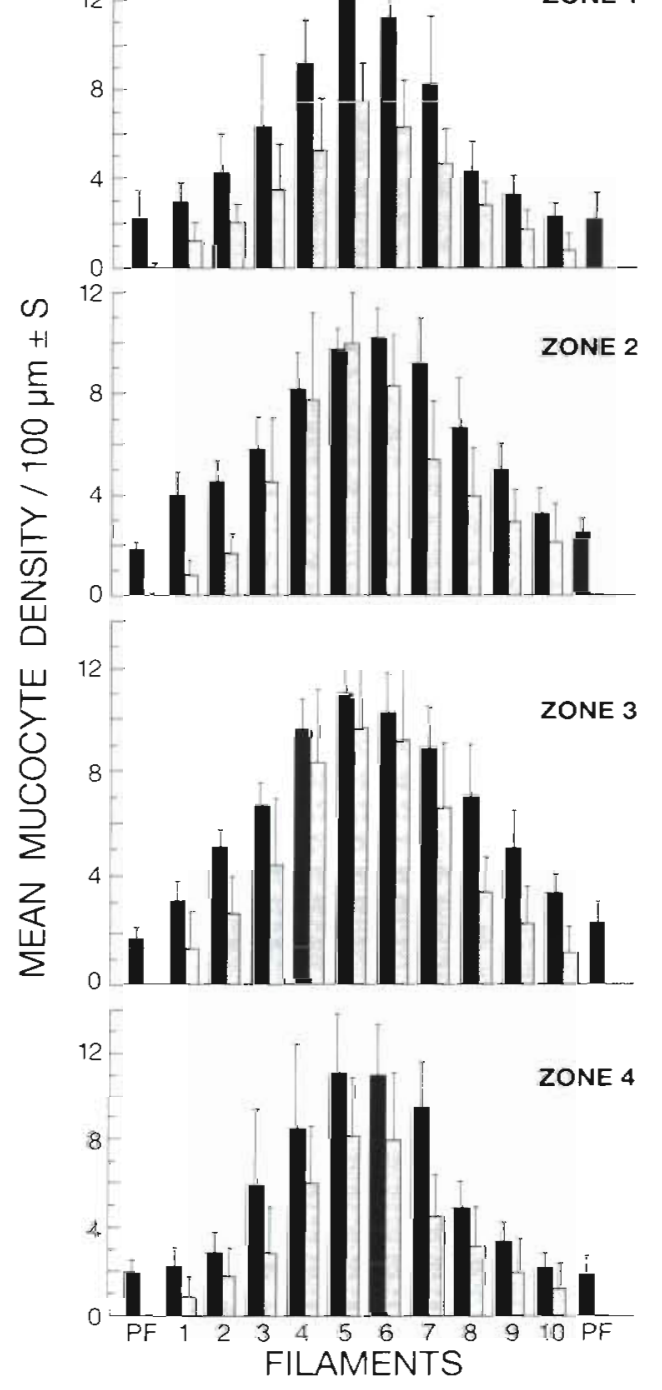

acid secretion

ZONE 1
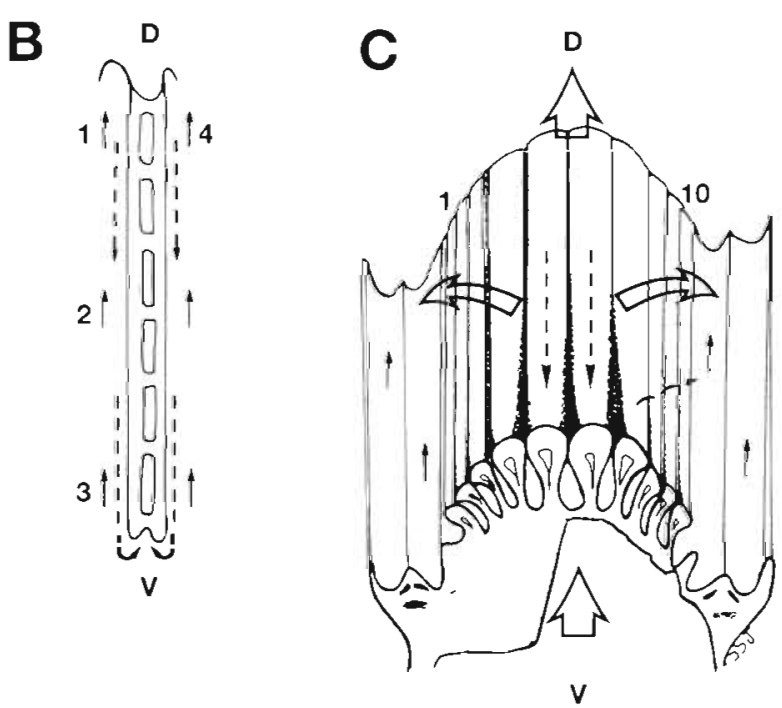

Fig. 3. Crassostrea virginica. Mean murocyte densities and particle transport on the gill. (A) Mean mucocyte densities for $100 \mathrm{~mm}$ lengths of gill filament for each of the 4 counting zones on the filaments of a complete plica. (B) Particle transport longitudinally on gill filaments. Solid arrows indicate direction of particles dorsally in principal filament troughs; dashed arrows show direction of particle transport on ordinary filament plical crests. 1-4 indicate mucocyte counting zones; $\mathrm{D}$ and $\mathrm{V}$ : dorsal and ventral orientations. (C) Details of particle transport and water currents on the gill, as described by Ward et al. (1994). Large open arrows show direction of water currents above the gill, with lateral currents carrying particles into the principal filament troughs; large dashed arrows show ventralward movement of particies on ordinary filament plical crest; small dashed arrow shows occasional transier of particles from the OF plica to the PF troughs. 1 and 10 indicate OF numbers used for counts presented in Fig. 2.1 
increase the viscosity of the mucus cord as it approaches the labial palp; this would facilitate the transfer of material onto the palp via a suspended mucus 'bridge', as observed in the endoscopic study of Ward et al. (1994).

In addition to particles being transported ventrally and incorporated into a mucus-particle cord, particles have also been observed travelling dorsally in suspension' in the principal filament troughs (Ward et al. 1994). The principal filament trough contains very few mucocytes, and these are all AMPS mucocytes aligned on a median ridge (Figs, 1 \& 3). This median ridge, depicted in Nelson (1960), is formed by the contraction of muscles beneath the epithelium of the PF trough (Fig. 1). Particles captured on the plical sides rather than the crests travel laterally along successive OFs until reaching the PF trough, where they are then moved dorsally. These particles encounter essentially the same proportions of mucocyte types (but smaller numbers of each) as those moved ventrally on the plical crests (Fig. 3). It is thus likely that the particles travelling dorsally 'in suspension' in the PFs are accompanied by an acid-dominant mixture of mucopolysaccharides, yet no mucus cord is formed. This apparently contradictory observation suggests that the conditions for forming a mucus cord are a relatively large amount of acid-dominant mucus compressed into a tight space (the ventral particle groove). Whereas the gill has 2 PFs for each of the numerous plicae, it has only 1 ventral particle groove. Very large volumes of AMPS will therefore accumulate in this groove. This reasoning is supported by our knowledge of the structure of mucopolysaccharide gels, which may expand to various degrees when hydrated and mechanically mixed, as on ciliated epithelia (Silberberg 1989, Sleigh 1989). NMPS secretions hydrate very readily, while AMPS do not, due to the presence of stabilizing disulphide bonds (Silberberg 1989). The acid-dominant secretions of the oyster gill, which contain a considerable proportion of NMPS, will thus hydrate more readily in the principal filaments, since in this situation there are relatively low amounts of secretion, large amounts of water, and a relatively large volume available for expansion.

The disposition of a single row of AMPS mucocytes along the median ridge of the PFs may explain the extremely wide range of particle velocities recorded for the PF troughs 366 to $1225 \mathrm{\mu m} \mathrm{s}^{-1}$; Ward et al. 1994) When erect, the highly viscous AMPS ridge secretions could intercept some particles travelling dorsally in a mucus-water slurry. These particles would then be transported much more slowly along the ciliated epithelium of the median ridge. It should be noted that particles travel ventrally on the OF plica crest at 70 to $163 \mu \mathrm{m} \mathrm{s}$, against the current flow, whereas particles transported along the median ridge would travel dorsally with the current flow The presence of 2 transport mechanisms with different velocities within the PF trough would allow a great degree of flexibility in forwarding particles to the buccal region, perhaps even minimizing the problems of overload under high particle concentrations typical of the oyster habitat.

To this point, the gill mucocyte distribution has been determined for 3 bivalve species belonging to 3 different families and 3 different gill types (Table 1). None of these species has the same profile of mucocyte distribution or secretion type; however, certain common principles emerge. Regardless of species or gill type, acid or acid-dominant mucopolysaccharides are always involved in movement of particles on exposed surfaces, counter to the dominant water current (i.e. ventralward on the gill: Mytilus edulis, Crassostrea virginica). On surfaces which are more enclosed, and where particles are transported with the current flow (i.e. the principal filament troughs), the transport medium contains either very little mucus, albeit aciddominant and maximally hydrated ( $C$. virginica), or a larger amount of similarly hydrated intermediate viscosity mucus (Placopecten magellanicus). Thus, despite the diversity of gill and mucocyte secretion types, a unifying principle appears to operate in the transport of particles on the gill of suspension-feeding bivalves.

Acknowledgements. The authors thank Mad. S. D. St-Jean for the drawings of Figs. 1 \& 2, as well as M. L. Blanchard for his photographic work. Mad. J. Bourque provided mucocyte diameters and additional counts in the anterior gill region. This research was carried out with the assistance of an NSERC operating grant to P.G.B. and an NSERC summer scholarship to S.D.

\section{LITERATURE CITED}

Beninger PG, Le Pennec $M$ (1993) Histochemistry of the bucco-oesophageal glands of Mytilus edulis: the importance of mucus in ingestion. J Mar Biol Ass UK 73: $237-240$

Beninger PG, Le Pennec M, Donval A (1991) Mode of partıcle ingestion in five species of suspension-feeding bivalve molluscs. Mar Biol 108:255-261

Beninger PG, St-Jean S, Poussart Y, Ward JE (1993) Gill function and mucocyte distribution in Placopecten magellanicus and Mytilus edulis (Mollusca: Bivalvia): the role of mucus in particle transport. Mar Ecol Prog Ser 98:275-282

Beninger PG, Ward JE, MacDonald BA, Thompson RJ (1992) Gill function and particle transport in Placopecten magellanicus (Mollusca: Bivalvia) as revealed using video endoscopy. Mar Biol 114:281-288

Cook HC (1990) Carbohydrates. In: Bancroft JD. Stevens A. (eds) Theory and practice of histochemical techniques. Churchill Livingstone, London, p 177-215 
Grenon JF, Walker G (1978) Hustology and histochemistry of the pedal glandular system of two limpets, Patulla vulgata and Acmea tessulata (Gastropoda: Prosobranchia). J Mar Biol Ass UK 58:803-806

Grenon JF, Walker $G$ (1980) Biochemical and rheological properties of the pedal mucus of the limpet, Patella vutgata L. Comp Biochem Physiol 66B:451-458

Levinton JS (1977) Ecology of shallow water deposit-feeding communities, Quisset Harbor, Massachusetts. In: Coul] BC (ed) Ecology of marine benthos. University of South Carolina Press, Columbia, p 191-227

Nelson TC (1960) The feeding mechanism of the oyster. II. On the gills and palps of Ostrea eduils, Crassostrea virginica, and C. angulata. J Morph 107:163-191 + 2 plates

Owen G (1978) Classification and the bivalve gill. Phil Trans R Soc Lond B 194:527-544

Ribelin BW, Collier A (1977) Studies on the gill ciliation of the American oyster Crassostrea virginica (Gmelin). J Morph 151:439-450

Silberberg A (1989) Mucus glycoprotein, its biophysical and

This article was presented by $J$. M. Lawrence (Senior

Editorial Advisor), Tampa, Florida, USA gel-forming properties. In: Chantler E, Ratcliffe NA (eds) Mucus and related topics. The Company of Biologists Ltd Cambridge, p 43-63

Sleigh MA (1989) Adaptations of ciliary systems for the propulsion of water and mucus. Comp Biochem Physiol 94A:359-364

Tankersley RA, Dimock RV Jr (1992) Quantitative analysis of the structure and function of the marsupial gills of the freshwater mussel Anodonta cataracta. Biol Bull 182 $145-154$

Tankersley RA, Dimock RV Jr (1993) Endoscopic visualization of the functional morphology of the ctenidia of the unionid mussel Pyganodon cataracta. Can J Zool 71:811 819

Ward JE, MacDonald BA, Thompson RJ, Beninger PG (1993) Mechanisras of suspension-teeding in buvalves: resolution of current controversies by means of endoscopy. Limnol Oceanogr 38:265-272

Ward JE, Newell RIE, Thompson RJ, MacDonald BA (1994) In vivo studies of suspension-feeding processes in the eastern oyster, Crassostrea virginica (Gmelin). Biol Bull $186: 221-240$

Manuscript irst received: September 6, 1995

Revised version accepted: February 20, 1996 